REVIEW

\title{
Doctor-to-patient transmission of viral hepatitis B: is it a problem, is there a solution?
}

Solko W. Schalm ${ }^{1}$ and Jan K. van Wijngaarden ${ }^{2}{ }^{1}$ Department of Hepatogastroenterology, University Hospital Rotterdam and ${ }^{2}$ Inspectorate of Health Care, Ministry of Health, Welfare and Sport, The Hague, the Netherlands

SUMMARY. It is well-established that hepatitis B may be transmitted from surgeons to their patients. Clear strategies are needed to reduce the risk of transmission whilst not discriminating unnecessarily against surgeons who may pose no risks to their patients. This review outlines the current position and provides a blueprint for action that may reduce the risks to patients whilst minimizing the impact on practising surgeons.

Keywords: hepatitis B, medical personnel, transmission.

\section{DOCTOR-TO-PATIENT TRANSMISSION OF HEPATITIS B: A PROBLEM?}

In 1991 the Centers for Disease Control (CDC) updated the recommendations for preventing transmission of hepatitis $\mathrm{B}$ virus (HBV) and human immunodeficiency virus (HIV) to patients during exposure-prone invasive procedures [1]. Based on analysis of reports in the literature and a prospective CDC study, the document states that infected health care workers (HCW) who adhere to universal precautions and who perform certain exposure-prone procedures pose a small risk for transmitting $\mathrm{HBV}$ to patients. The risk of transmitting HIV is much less. Infected HCWs who adhere to universal precautions and who do not perform invasive procedures pose no risk for transmitting HIV or HBV to patients.

Despite adherence to universal precautions, transmission of HBV has been reported during certain oral, cardiothoracic, colorectal and obstetric/gynaecological procedures. In the prospective study, percutaneous injuries occurred among surgical personnel during $6.9 \%$ of operative procedures on the general surgery, gynaecology, orthopaedic, cardiac and trauma services. Percutaneous exposure of the patient to the HCW's blood may have occurred when the sharp object causing the injury recontacted the patient's open wound in $32 \%$ of the observed injuries to surgeons. The risk of doctorto-patient blood contact is thus $\approx 3 \%$. Characteristics of exposure-prone procedures include digital palpation of a needle tip in a body cavity or the simultaneous presence of

Abbreviations: HBV, hepatitis B virus; HCW, health care worker; HIV, human immunodeficiency virus.

Correspondence: Prof. Dr S.W. Schalm, Department of Hepatogastroenterology, University Hospital Rotterdam, PO Box 2040, 3000 CA Rotterdam, the Netherlands. the HCW's fingers and a needle or other sharp instrument in a poorly visualized anatomic site.

In the period 1974-90, there were 20 published reports in which treatment by a HBV-infected HCW was associated with transmission of $\mathrm{HBV}$. In 12 of these clusters, the implicated HCW did not routinely wear gloves. In the remaining eight clusters, transmission occurred despite glove use. Of the HCWs whose hepatitis B e antigen (HBeAg) status was determined (17 of 20), all were $\mathrm{HBeAg}$ positive. The presence of HBeAg in serum reflects a phase of HBV infection with high levels of circulating virus and great infectivity.

Seven of the HCWs who were linked to published clusters in the United States continued to perform invasive procedures following modification of invasive techniques (double gloving and restriction of certain high-risk procedures). For five HCWs, no further transmission to patients was observed; in two instances, HBV was transmitted to patients after techniques were modified [1].

Since 1991 there have been nine published reports on HCW-patient transmission of HBV according to MEDLINE. The focus on these reports were unusual features such as transmission by HBeAg-negative surgeons [2-4], severe outcome of the HBV infection [2] or severe consequences for the surgeon involved [5,6]. The number of published reports, however, may not reflect the magnitude of the problem. In the UK a registry has been set up after the investigation in the early 1990s; this registry now contains seven cases since 1993, which suggests a public health problem of greater extent than generally anticipated. This concept is supported by the surfacing of two incidents in the last 5 years in the Netherlands, a country of 15 million inhabitants. An article in the lay-press that widely publicized a case of HBV transmission by a cardiac surgeon in Aachen, Germany which 
also involved Dutch patients, was recently followed by an cluster of cases in the south of the Netherlands.

Clearly in an age of increased efforts to prevent hepatitis B transmission by blood transfusion, the problem of transmission of HBV from surgeons to patients should be addressed more thoroughly.

Thus, to answer the first question of this article: yes, there is a problem. The problem appears confined to surgeons who perform exposure-prone proceedures. However, the problem is not limited to those who are $\mathrm{HBeAg}$ positive.

\section{HEPATITIS B VIROLOGY AND THE RISK OF TRANSMISSION}

In the CDC survey all HCWs implicated in transmitting HBV to patients were $\mathrm{HBeAg}$ positive. The HBeAg is a nonstructural viral protein and unlikely to be directly associated with the infectivity of inapparently transmitted blood. HBeAg should be considered a marker of high levels of circulating virus, and the level of viraemia has been found to be associated with the risk of perinatal HBV transmission [7].

In the 1990s there was increased awareness that HBeAgnegative mutants of HBV may also reach high levels of viraemia, and that the occurrence of this type of $\mathrm{HBV}$ is not confined to the countries around the Mediterranean Sea.

It is therefore to be anticipated that a more reliable estimate of infectivity can be obtained by testing serum for the viral load of HBV. In Germany this approach has been followed since 1992. The German Society of Virology has recommended that $\mathrm{HBeAg-positive} \mathrm{HCWs}$ with $\leq 10^{5} \mathrm{HBV}$ genomes $\mathrm{ml}^{-1}$ of serum need not be excluded from exposureprone work [8]. With regard to this recommendation it is important to know the serum levels of HBV of the HBeAgnegative surgeons implicated in transmission of HBV. In fact, all of the four $\mathrm{HBeAg}$-negative surgeons who transmitted HBV had serum HBV DNA concentrations higher than $10^{5}$ genomes $\mathrm{ml}^{-1}[3]$.

The German authors point to an important aspect if their recommendation is to be widely adopted, namely that of the need for accurate assays of HBV DNA. Available commercial test kits have good reproducibility, but use highly divergent standards. Most assays underestimate the true number of genomes by a factor of 10-50 [9-11]. All four infected surgeons had greater than $10^{7}$ genomes if the published genome concentrations are corrected. If one corrects the original recommendation in view of the new calibrations, the current recommendation would be to institute specific measures only for surgeons with greater than $10^{6}$ genomes $\mathrm{ml}^{-1}[8]$.

\section{THE SOLUTION}

In the CDC guidelines of 1991 recommendations with regard to $\mathrm{HBV}$ were made:
- HCWs who perform exposure-prone procedures and who do not have serological evidence of immunity to HBV from vaccination or from previous infection should know their hepatitis B surface antigen (HBsAg) status and, if that is positive, should also know their HBeAg status.

- HCWs who are infected with HBV and are HBeAg positive should not perform exposure-prone procedures unless they have sought counsel from an expert review panel and been advised under what circumstances, if any, they may continue to perform these procedures.

These guidelines appear — today — still a sensible approach to the problem if $\mathrm{HBeAg}$ testing is replaced by quantitative testing of HBV DNA.

The underestimation of the risk of HBV transmission by surgeons, however, has led to minimal endorsement of these guidelines in many countries in Europe and probably elsewhere in the world. Whereas HBV vaccination of HCWs is now common practice, the follow-up of those who have not responded to the vaccine is often incomplete, in particular with regard to HBsAg, HBeAg and HBV DNA testing. Also, national or regional review panels consisting of an infectious disease specialist with expertise in the epidemiology of HBV transmission, a hospital epidemiologist, a laboratory virologist and a state or local public health official, are almost nonexistent (such review panels should be completed in each case with the HCW's personal physician and a health professional with expertise in the procedures performed by the HCW).

Thus, to answer the second question of this article: yes, there is a solution to the problem. The solution needs to be implemented first by endorsement of the national health board of the (modified) guidelines of the CDC and second by extensive advertisement of the guidelines among the HCW societies, in particular the surgical societies.

\section{THE HBsAg-POSITIVE SURGEON}

Specific measures to limit HCWs in their profession are based on epidemiological evidence of the risk of transmission. In that setting, doctor-to-patient transmission of $\mathrm{HBV}$ has not been documented in HCWs who adhere to universal procedures and have HBV DNA levels of $10^{6}$ genomes $\mathrm{ml}^{-1}$ or less (corrected methodology). Therefore, unless new evidence emerges and allowing for a safety margin, it could be proposed that the HBsAg-positive surgeon with repeated measurements of $0.5-1 \times 10^{5}$ genomes $\mathrm{ml}^{-1}$ or less should be allowed to carry out normal professional work without restrictions.

HBsAg-positive individuals with $\mathrm{HBV}$ DNA $<10^{6}$ genomes $\mathrm{ml}^{-1}$ are usually $\mathrm{HBeAg}$ negative. In the large majority the HBV infection remains stable, particularly if serum aminotransferase (ALT) levels are normal. In those with elevated serum ALT, hepatitis flares associated with increased levels of HBV DNA occur in $\approx 5 \%$ of individuals per year. It 
appears prudent to monitor those individuals regularly to allow intervention to minimize the risk of transmission and the progression of their liver disease.

The HBsAg-positive surgeon with HBV DNA greater than $10^{6}$ genomes $\mathrm{ml}^{-1}$ then poses a risk of transmitting HBV to his patients and specific measures are needed. Much of the discussion in the literature has focused on restrictions to perform exposure-prone procedures or all procedures. This approach is sensible from the viewpoint of the public health sector that assumes limited possibility in modifying the level of viraemia in the infected person. The proven effect of antiviral therapy in reducing the transmission of HIV from pregnant women to their babies [13], however, suggests that the approach of medically reducing viraemia is feasible and could also be applicable to HBV transmission.

Lamivudine is an oral drug with strong anti-HBV activity. The drug, which has minimal side-effects and can be taken for years, reduces the level of HBV DNA to below $10^{7}$ genomes $\mathrm{ml}^{-1}$ in $60-90 \%$ of patients, and HBeAg seroconversion is observed in $\approx 20 \%$ [14]. Therefore, in a proportion of HBsAg-positive surgeons, high-level viraemia might be adequately suppressed by lamivudine monotherapy. In fact, such an approach has been successfully applied in practice (Fig. 1).

Long-term lamivudine monotherapy is associated with non-compliance or emergence of resistance in $14-38 \%$ of individuals after 1 year [14,15] and in up to $50 \%$ after 3 years [16]. Therefore, it is mandatory that regular monitoring of HBV DNA is instituted. The concept of antiviral therapy for HBsAg-positive surgeons with high-level viraemia will - in all likelihood - develop further with the introduction of other effective anti-HBV drugs [17] and combination therapy $[18,19]$.

HBsAg-positive surgeons found to have high-level viraemia should consider antiviral therapy; if virus suppression is successful, it could open the possibility of returning to a full range of professional work.

\section{IMPLEMENTATION}

Once a scientifically sound policy for HBsAg-positive HCWs is proposed, it is necessary to gain support for this policy, both from the professional groups (i.e. health care personnel performing high-risk procedures) and from the public at

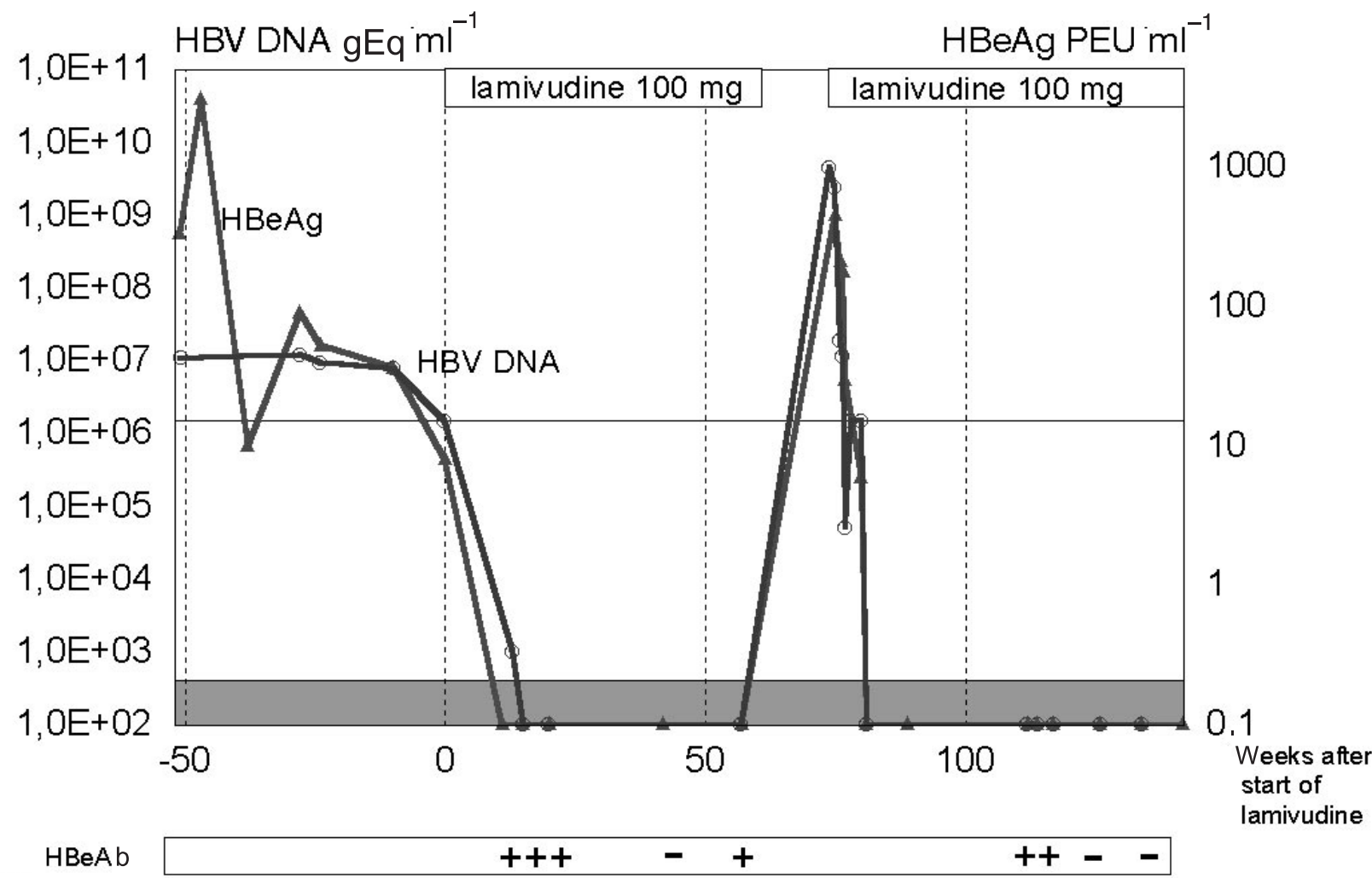

Fig. 1 In a health care worker (HCW) lamivudine monotherapy rapidly reduces serum hepatitis B virus (HBV) DNA levels to below $10^{6}$ genomes $\mathrm{ml}^{-1}$ with a parallel fall in hepatitis B e antigen (HBeAg) expressed in Paul Ehrlich units ml ${ }^{-1}$. In this patient HBV DNA in serum became undetectable by sensitive polymerase chain reaction (PCR) (detection limit $<400$ genomes $\mathrm{ml}^{-1}$ ) in conjuction with a HBeAg seroconversion. After withdrawal of therapy parameters of viral replication returned to pretreatment levels. Reintroduction of lamivudine successfully resuppressed viral replication. gEq $\mathrm{ml}^{-1}$, genome equivalents $\mathrm{ml}^{-1}$; HBeAb, antibody to hepatitis $\mathrm{B}$ e antigen. 
large. This support is necessary in order to establish actual practice guidelines.

This process involves three steps:

1 The first step is submitting the proposed policy to a group of experts, representing the scientific community. In the Dutch situation this means that the National Health Council, the scientific advisory board for the government on health matters, must explicitly consent to the proposal.

2 A second step involves discussing the policy with the societies that represent the professional groups involved, such as surgeons. Based on the overall prevalence of HBV in the Netherlands [20] and the number of registered specialists performing surgery [21], it can be inferred that testing all involved specialists for hepatitis B carriership would result in identifying 10-20 physicians in the Netherlands as carriers. It can be expected that the concept of banning all carriers from performing high-risk procedures will meet resistance. Reducing this number by introducing HBV DNA levels as an additional criterion, and facilitating antiviral therapy in those with high-level viraemia, would make it easier to accept practice guidelines. The establishment of a panel of experts to consider individual cases might be an important additional feature to persuade the professional societies.

3 The third step should warrant the acceptance by the public at large, the future patients. In the Dutch situation, patient's groups are, at a national level, represented by the Federation of Patients and Consumer Organizations in the Netherlands. This federation is usually involved in policy discussions involving patients' rights. For (future) patients (and the organization representing them), it might be difficult to accept that HCWs, who are carriers of the virus, will be allowed to continue to perform exposure-prone procedures. However, if the proposed policy is scientifically sound, it is up to the Federation to come forward with an alternative solution that in an equally fair way balances the rights of the professionals and the patients.

As every HCW is obliged to provide appropriate care, it seems a logical step that the professional societies themselves endorse the practice guidelines and inform their members.

The management of hospitals and other health care providers has its own responsibility to protect the safety of patients for whom they provide care. Therefore, it should enforce adherence to the guidelines.

Last but not least, the Inspectorate of Health Care, the Ministerial body for assessment of quality of health care, will supervise the implementation of the proper guidelines and, if necessary, impose them.

Once the guidelines are implemented, it follows that the management of health care providers will require information regarding the HBV status of all HCWs that perform exposure-prone procedures. If a carrier state is established, proof must be submitted that HBV DNA levels are and remain within the accepted limits. For the carrier this means granting permission to disclose the results of the pertaining serum tests to a (by the management) designated person.

As information regarding the HBV status will have to be submitted in certain circumstances during their professional career, it is in the interest of medical students to be aware of their HBV status at an early stage. If treatment does not result in acceptable HBV DNA levels, they can choose a medical career that does not involve performing exposureprone procedures. When would be the right moment to establish the HBV status of medical students?

Obviously, it should be linked to well-established policy to immunize medical students against hepatitis B [22]. Good immunization practice includes checking the postvaccination hepatitis B surface antibody (HBsAb) titre. This procedure can be expanded to identify a carrier state in the case of non-responders. Immunization and serological follow-up could be linked to the preclinical training in virology.

In our opinion, medical students who are non-responders, but have been shown to be non-carriers, should be allowed to perform exposure-prone procedures, on the condition that they are checked at regular intervals for hepatitis B infection, e.g. every 6-12 months.

\section{ACKNOWLEDGEMENTS}

The authors thank D. Shouval, W. H. Gerlich, H. Nicholas and R. A. de Man for the information, advice and for the critical reading of the manuscript.

\section{REFERENCES}

1 Centers for Disease Control. Recommendation for preventing transmission of human immunodeficiency virus and hepatitis B virus to patients during exposure-prone invasive procedures. MMWR, 1991; 40 (RR08): 1-9.

2 Sundkvist T, Hamilton GR, Rimmer D, Evans BG, Teo CG. Fatal outcome of transmission of hepatitis B from an e antigen negative surgeon. Commun Dis Public Health 1998; 1: 48-50.

3 The Incident Investigation Teams. Transmission of hepatitis B to patients from four infected surgeons without hepatitis Be antigen. N Engl J Med 1997; 336: 178-184.

4 Halle M. Surgeon had mutant form of hepatitis B. BMJ 1996; 313: 771 .

5 Jones D. Hepatitis leaves Halifax surgeon an operating room outcast. CMAJ 1991; 145: 1345-1346.

6 Dyer C. Surgeon jailed for infecting patients. BMJ 1994; 309: 896.

7 Ip HMH, Lelie PN, Wong VCW, Kuhns MC, Reesink HW. Prevention of hepatitis B virus carrier state in infants according to maternal serum levels of HBV DNA. Lancet 1989; 1: 406-410.

8 Caspari G, Gerlich WH. Mandatory hepatitis B virus testing for doctors. Lancet 1998; 352: 991.

9 Janssen HLA, Schoenmaker-Weber YAM, Kruining J, Schalm SW, Heijtink RA. Quantitative assessment of 
hepatitis B virus DNA in chronic hepatitis B patients: comparison of two solution hybridisation assays. J Med Virol 1993; 40: 307-312.

10 Zaaijer HL, ter Borg F, Cuypers HT, Hermus MC, Lelie PN. Comparison of methods for detection of hepatitis B virus DNA. J Clin Microbiol 1994; 32: 2088-2091.

11 Heerman KH, Gerlich WH, Chudy M, Schaefer S, Thomssen R. Quantitative detection of hepatitis B virus DNA in two international reference plasma preparations. Eurohep Pathobiol Group J Clin Microbiol 1999; 37: 68-73.

12 Liaw YF, Tai DI, Chu CM, Pao CC, Chen TJ. Acute exacerbation in chronic type B hepatitis: comparison between $\mathrm{HBeAg}$ and antibody-positive patients. Hepatology 1987; 7: 20-23.

13 Mofenson LM. Short-course zidovudine for prevention of perinatal infection. Lancet 1999; 353: 766-767.

14 Lai CL, Chien RN, Leung NW et al. A one-year trial of lamivudine for chronic hepatitis B. N Engl J Med 1998; 339: 61-68.

15 Honkoop P, de Man RA, Niesters HGM, Schalm SW. Clinical impact of lamivudine resistance in chronic hepatitis B. J Hepatol 1998; 29: 510-514.

16 Leung NWY, Lai CL, Chang TT et al. Three year lamivudine therapy in chronic HBV. J Hepatol 1999; 30: 59S.
17 Gibbs CS, Westland CW, Yang $\mathrm{H}$ et al. In vitro analysis of cross-resistance profiles of new antivirals for chronic HBV infection. J Hepatol 1999; 30: 62S.

18 Schalm SW, Heathcote J, Cianciara J et al., on behalf of an International Lamivudine Study Group. Lamivudine and alpha interferon combination treatment of patients with chronic hepatitis B infection: a randomized trial. Gut 2000; 46: 562-568.

19 Alexopoulou A, Zafiropoulou R, Papakonstantinou A, Hadziyannis SJ. Randomised trial in HBeAg negative patients with replicating virus with ganciclovir vs lamivudine in combination with interferon. Evaluation of long-term efficacy. Hepatology 1998; 28: 490A.

20 Marrewijk CJ, Veldhuijzen IK, Conyn-van Spaendonck MAE, Kooy H, van den Hof S, Dorigo-Zetsma JW. Prevalence of hepatitis B viral markers in the Dutch population: a population-based serosurveillance study (PIENTER project) Bilthoven, RIVM. report no. 243680001, 1999 National Institute of Health.

21 Official Registry based on the Individual Health Care Professions Act Ministry of Health, Welfare and Sport, (1999) The Hague.

22 Health Council of the Netherlands. Committee Hepatitis B Protection against hepatitis B. Health Council of the Netherlands. Publication no. 1996/15, 1996 Rijswijk. 